\title{
Effects of Various Doses of Growth Hormone on Serum Total Cholesterol, Phospholipid, and Bile Acid in a Patient with Cholestasis
}

\author{
Hiromasa NODA, Hirokazu SATO and Hironori NAKAJIMA \\ Department of Pediatrics, Funabashi Central Hospital, \\ Chiba 273, Japan
}

\begin{abstract}
To determine whether growth hormone (GH) has any impact on the hyperlipidemia seen in cholestatic patients, graded doses of $\mathrm{GH}$ in the sequence of $0.1,0.2,0.4$, and $0.6 \mathrm{u} / \mathrm{kg}$ every other day were administered sc to a patient with Alagille syndrome.

Serum total cholesterol, phospholipid, and bile acid were measured. The serum levels of all three decreased markedly after GH administration and the lowest levels were observed on the second day after the GH dose of $0.4 \mathrm{u} / \mathrm{kg}$. However, they increased thereafter despite the administration of an increased dose of $\mathrm{GH}$; especially the serum bile acid level returned to the initial value by day 8 .

Serum levels of SM-C and fT3 were not correlated with the changes in total cholesterol, phospholipid, and bile acid after GH administration.

We suggest that the administration of GH may affect the state of hyperlipidemia seen in cholestatic patients.
\end{abstract}

Physiologic and clinical studies suggest that GH has many effects on carbohydrate, protein and lipid metabolism (Konobil, 1966; Raiti and Blizzard, 1970 ; Merimee and Rabin 1973). The reports dealing with the effect of $\mathrm{GH}$ on serum lipids are controversial (Friedman et al., 1970; Friedman et al., 1974 ; Aloia et al., 1975 ; Winter et al., 1979; Merimee and Pylkkinen, 1980; Blackett et al., 1982; Asayama et al., 1984). Most of the above reports were limited to the subject of GH deficiency with only mild hypercholesterolemia, except for the study of Friedman et al. (1974) in which they found that daily administration of a very high pharmacologic dose of $\mathrm{GH}(25 \mathrm{u})$ to even normocholesterolemic and moderately hypercholesterolemic adults who had no reported GH deficiency caused a decrease in their serum cholesterol concentrations in one week. The effect of $\mathrm{GH}$ on the hyperlipidemia of cholestatic patients has not been studied, although such a study may help to find the exact effect of $\mathrm{GH}$ on serum lipid.

This report describes the effect of $\mathrm{GH}$ on hyperlipidemia in a boy with Alagille syndrome. 


\section{Materials and Methods}

\section{Subject}

An 8-year-old boy with Alagille syndrome was studied. His height was $109.2 \mathrm{~cm}(-2.86$ $\mathrm{SD}$, height age $5 \% / 12 \mathrm{yr}$ ) and his weight was $20.5 \mathrm{~kg}$. Bone age determined by the standards of Greulich and Pyle was 5 yr. Peak serum $\mathrm{GH}$ levels during an insulin-arginine tolerance test when he was 7 years old were 16 and $6.2 \mathrm{ng} /$ $\mathrm{ml}$, respectively. Serum SM-C was $0.38 \mathrm{IU} / \mathrm{ml}$. He has had chronic cholestasis since his neonatal period. His liver function was disturbed after his birth but improved and remained stable after he was 6 years old. Although hyperbilirubinemia disappeared after infancy, serum total cholesterol and bile acid levels remained high. The yearly laboratory data since his birth are summarized in Figure 1. His face is characteristic of the syndrome, with prominent forehead, moderate hypertelorism, deepset eyes, small chin, and

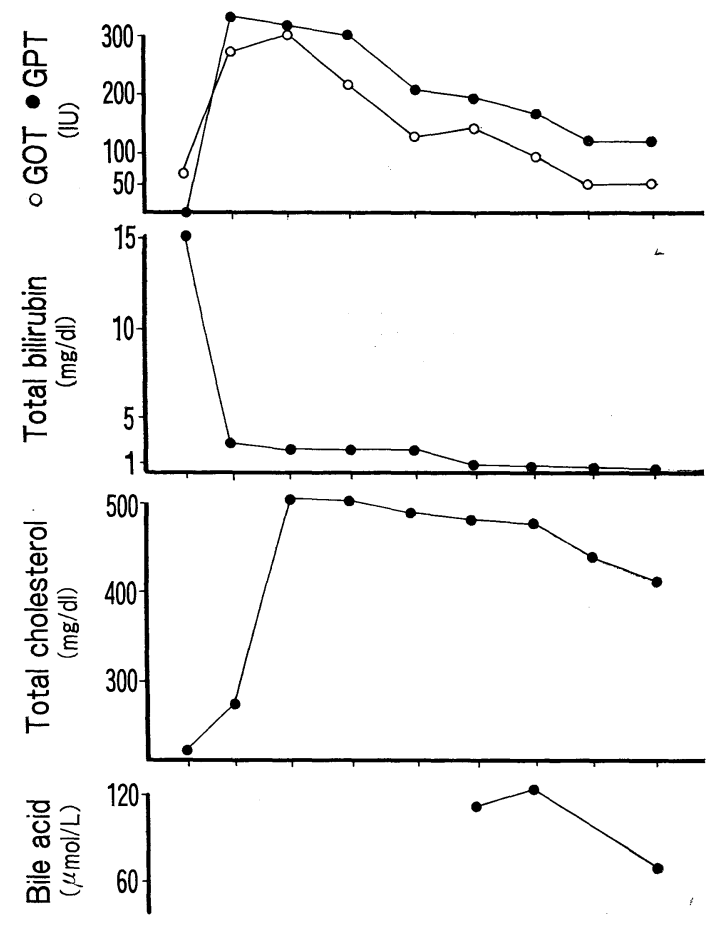

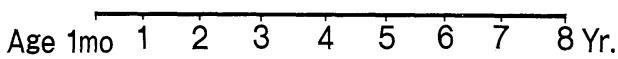

Fig. 1. The yearly laboratory data after birth. saddle nose. He also has peripheral pulmonary stenosis.

\section{Study protocol}

The patient was asked not to modify his diet until after all the blood specimens were obtained. In considering the half life of human growth hormone (hGH) and SM-C, and to determine whether the effect of $\mathrm{GH}$ on hyperlipidemia is dose dependent or not, graded doses of $\mathrm{hGH}$ in the sequence of $0.1,0.2,0.4$, and $0.6 \mathrm{u} / \mathrm{kg}$ every other day were administered sc to this patient at 15:00. Blood samples were drawn at the same time and samples were drawn on the day of hGH injection before the injection. The plasma was separated immediately and stored frozen at $-20^{\circ} \mathrm{C}$ until the assay. A total of nine samples were collected for the determination of total cholesterol, phospholipid, bile acid, SM-C, and fT3 levels. All determinations were made in a single run to avoid interassay variations.

\section{Analytic methods}

Serum total cholesterol (Richmond, 1973), bile acid (Mashige et al., 1981), and phospholipid (Takayama et al., 1977) were all measured with commercial kits. SM-C was assayed with a double antibody RIA Kit (Eiken Immunochemical Laboratory, Tokyo, Japan). FT3 was assayed with an Amerlex RIA Kit (Amersham International of PLC, Buckinghamshire, England).

\section{Results}

Laboratory data before, during and after the administration of various doses of $\mathrm{hGH}$ are summarized in Figure 2. Total cholesterol, phospholipid, and bile acid decreased from $362 \mathrm{mg} / \mathrm{dl}, 520 \mathrm{mg} / \mathrm{dl}$, and $72 \mu \mathrm{mol} / \mathrm{L}$ to $268 \mathrm{mg} / \mathrm{dl}, 381 \mathrm{mg} / \mathrm{dl}$, and $10.6 \mu \mathrm{mol} / \mathrm{L}$ respectively, two days after the injection of a low dose $(0.1 \mathrm{u} / \mathrm{kg})$ of $\mathrm{hGH}$. Their lowest levels $(214 \mathrm{mg} / \mathrm{dl}, 274 \mathrm{mg} / \mathrm{dl}$, and 3.5 $\mu \mathrm{mol} / \mathrm{L}$, respectively) were observed simultaneously one day after the third injection $(0.4 \mathrm{u} / \mathrm{kg})$. But thereafter rebounding increases were found with maximal levels of $256 \mathrm{mg} / \mathrm{dl}, 392 \mathrm{mg} / \mathrm{dl}$, and $300 \mu \mathrm{mol} /$, respectively, two days after the fourth injection 
$(0.6 \mu / \mathrm{kg})$. Four weeks after the course of hGH administration, total cholesterol, phospholipid, and bile acid had returned to high levels $(384 \mathrm{mg} / \mathrm{dl}, 548 \mathrm{mg} / \mathrm{dl}$, and 97.4 $\mu \mathrm{mol} / \mathrm{L}$, respectively) (Table 1 ).

SM-C increased after each dose of hGH. Although the magnitude of the increase in SM-C was small, it was dose dependent. FT3 showed no obvious changes after hGH

Table 1. hGH treatment

\begin{tabular}{lccc}
\hline \hline & Before & During & After (4 wks) \\
\hline $\begin{array}{l}\text { Bile acid } \\
(\mu \mathrm{mol} / \mathrm{L})\end{array}$ & 71.2 & 3.5 & 97.4 \\
$\begin{array}{l}\text { T. cholesterol } \\
(\mathrm{mg} / \mathrm{dl})\end{array}$ & 365 & 214 & 387 \\
$\begin{array}{l}\text { phospholipid } \\
(\mathrm{mg} / \mathrm{dl})\end{array}$ & 520 & 274 & 548 \\
\hline
\end{tabular}

Concentration of bile acid, total cholesterol and phospholipid before, during (the lowest levels) and 4 weeks after hGH administration. injection. Neither SM-C nor fT3 showed any changes correlated with total cholesterol, phospholipid, or bile acid.

\section{Discussion}

Previous studies dealing with the effect of $\mathrm{GH}$ on serum lipids are controversial (Friedman et al., 1970; Friedman et al., 1974; Aloia et al., 1975; Winter et al., 1979; Merimee and Pulkkinen et al., 1980; Blackett et al., 1982; Asayama et al., 1984). Treatment with GH lowered cholesterol concentrations in hypox rats (Friedman et al., 1970) and GH-deficient individuals in two studies (Blackett et al., 1982; Asayama et al., 1984) but had no effect in GH-deficient patients in two others (Winter et al.,

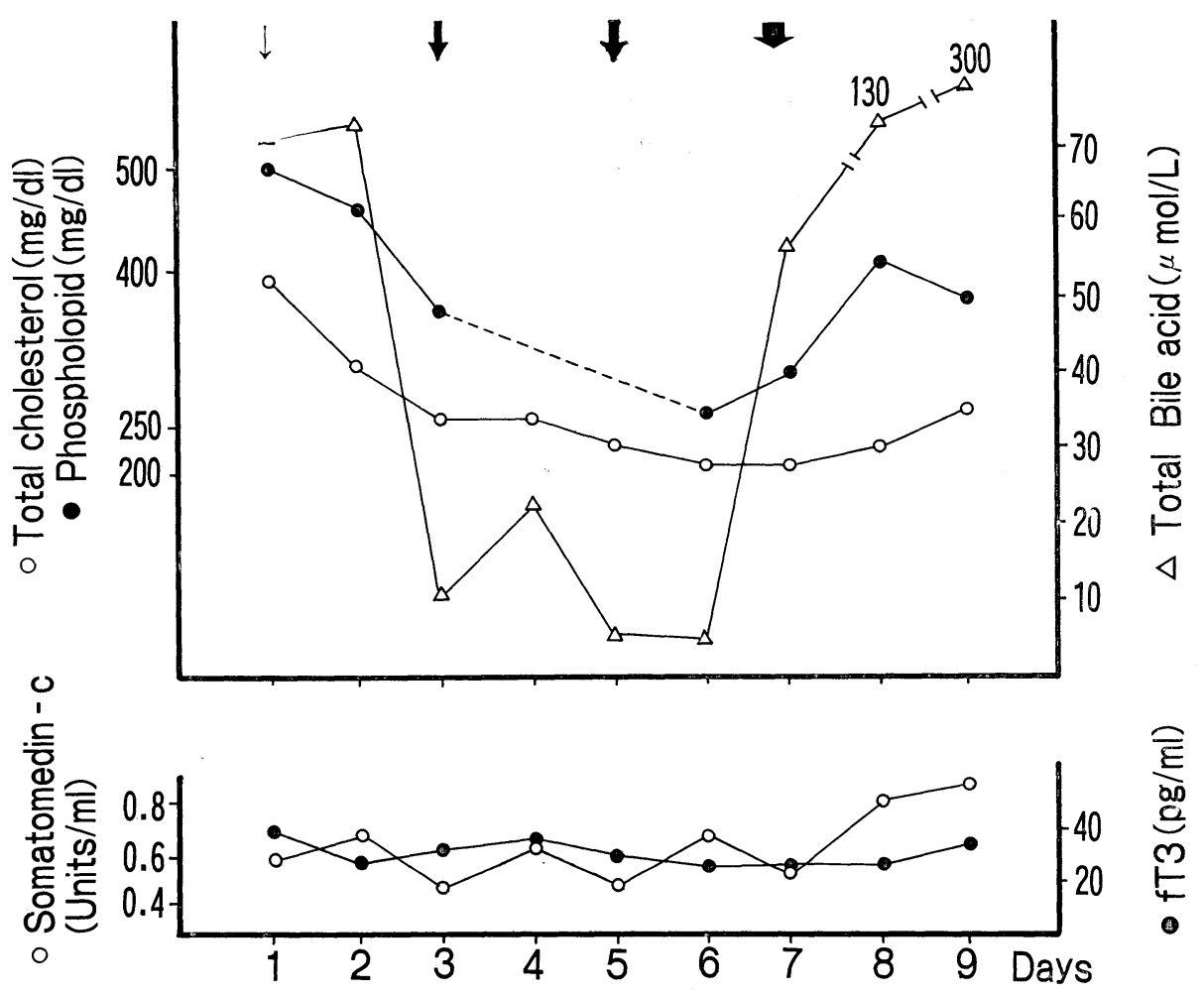

Fig. 2. Laboratory data before, during and after various doses of hGH administration. $\mathrm{HGH}$ dose : $\downarrow 0.1, \downarrow 0.2, \downarrow 0.4, \square 0.6 \mathrm{u} / \mathrm{kg}$. 
1979; Merimee and Fulkkinen, 1980). In normal individuals, GH caused a decrease in cholesterol after 1 week's administration of very large doses (Friedman et al., 1974) but not after 6 months' administration of lesser amounts (Aloia et al. 1975). The effect of $\mathrm{GH}$ on the hyperlipidemia seen in cholestatic patients has not been studied. Our results indicate that $\mathrm{GH}$ at a proper dose may lower not only the high level cholesterol but also the high levels of phospholipid and bile acid in cholestatic patients.

The basic defect leading to cholestasis in Alagille syndrome is not well known. In spite of the absence or paucity of intrahepatic bile ducts, variable amounts of bile secreted into the intestinal lumen can be demonstrated in the majority of patients 'with Alagille syndrome; extrahepatic biliary ducts are usually patent, although they can be hypoplastic (Watson and Miller, 1973; Henriksen et al. 1977 ; Grosse, 1979 ; Gorelick et al., 1982; Kahn et al., 1983; Markowitz et al., 1983). The intralobular bile is probably drained through a network of functional canaliculi to an area where bile ducts are patent. Patients with this syndrome have high levels of serum bilirubin and bile acid during infancy, but after that period bilirubin decreases to the normal level and the bile acid remains high (Riely et al., 1979). The dissociation between bile acid and bilirubin may indicate that a disturbance in bile acid secretion is involved in this syndrome. The precise mechanism of the dramatic decrease in serum bile acid after $\mathrm{hGH}$ administrations as found in this patient, although not clear, may be due to the enhancing effect of $\mathrm{GH}$ on bile acid secretion from canaliculi. Since the changes in serum levels of total choresterol and phospholipid were almost concomitant with the change in the serum bile acid level, the decreases in both may be due to the excretion of both from bile acid (Grundy and Metzger, 1972). But to confirm this, a study of the influence of GH on gallbladder bile composition, bile (concentration of cholesterol, bile acids, and phospholipids) would be necessary. The rebounding increases in total cholesterol, phospholipid, and especially bile acids after large doses of $\mathrm{hGH}(0.4$ and $0.6 \mathrm{u} / \mathrm{kg})$ may be explained by the feed-back secretion of somatostatin, since somatostatin has a cholestatic effect on bile secretion by enhancing ductal or canalicular bile reabsorption (Holm et al. 1978; Meyer et al., 1979; Ricci and Fevery, 1981 ; Rene et al., 1983).

Subclinical hypothyroidism developing during $\mathrm{GH}$ therapy may be related to the mild hypercholesterolemia seen in some GH-deficient subjects (Goodman et al., 1968; Porter et al., 1973) suggesting that thyroid hormone may have an effect on cholesterol metabolism. The administration of $\mathrm{hGH}$ did not change the concentration of fT3 in this patient, indicating that the reduction in serum cholesterol that was observed could not have been due to thyroid hormone. Changes in serum SM-C were not correlated with the changes in total cholesterol, phospholipid, and bile acid, suggesting that the three may not be related to SM-C.

\section{References}

Aloia, J. F., I. Zanzi and S. H. Cohn (1975). Absence of an effect of chronic administration of growth hormone on serum lipids. Metabolism 24, 795-799.

Asayama, K., S. Amemiya, S. Kusano and K. Kato (1984). Growth-hormone-induced changes in postheparin plasma lipoprotein lipase and hepatic triglyceride lipase activities. Metabolism 33, 129-131.

Blackett, P. R., P. K. Weech, W. J. McConathy and J. D. Fesmire (1982). Growth hormone in the regulation of hyperlipidemia. Metabolism 31, 117-120.

Friedman, M., S. O. Byers and S. R. Elek (1970). Pituitary growth hormone essential for regulation of serum cholesterol. Nature 225, 464-467.

Friedman, M., S. O. Byers, R. H. Rosenman. 
C. H. Li and R. Neuman (1974). Effect of subacute administration of human growth hormone on various serum lipid and hormone levels of hypercholesterolemic and normocholesterolemic subjects. Metabolism 23, 905912.

Goodman, H. G., M. M. Grumbach and S. L. Kaplan (1968). Growth and growth hormone. II. A comparison of isolated growth hormone deficiency and multiple pituitary-hormone deficiency in 35 patients with idiopathic hypopituitary dwarfism. N. Engl. J. Med. 278, $57-68$.

Gorelick, F. S., J. W. Dobbins, M. Burrell and C. A. Riely (1982). Biliary tract abnormalities in patients with arteriohepatic dysplasia. Dig. Dis. Sci. 27, 815-820.

Grosse, K. P. (1979). Die arteriohepatische dysplasie. Leber. Magen. Darm. 9, 247-252.

Grundy, S. M. and A. L. Metzger (1972). A physiological method for estimation of hepatic secretion of hepatic secretion of biliary lipids in man. Gastroenterology 62, 1200-1217.

Henriksen, N. T., H. Langmark, S. J. Sorland, O. Fausa, S. Landaas and O. Agenaes (1977). Hereditary cholestasis combined with peripheral pulmonary stenosis and other anomalies. Acta Pediatr. Scand. 66, 7-15.

Holm, I., L. Thulin, H. Samnegard, S. Efendic and T. Gunner (1978). Anticholeretic effect of somatostain in anesthetized dogs. Acta Physiol. Scand. 104, 241-243.

Kahn, E. I., F. Daum, J. Markowitz, H. W. Aiges, K. M. Schneider, H. B. So, P. Altman, R. S. Chandra and M. Silverberg (1983). Arteriohepatic dysplasia. II. Hepatobiliary morphology. Hepatology 3, 77-83.

Knobil, E. (1966). The pituitary growth hormone: An adventure in physiology. Physiology (Bethesda) 9, 25-32.

Markowitz, J., F. Daum, E. I. Kahn, K. M. Schneider, H. B. So, R. P. Atman, H. W. Aiges, G. Alperstein and M. Silverberg (1983). Arteriohepatic dysplasia. I. Pitfalls in diagnosis and management. Hepatology 3, 74-76.

Mashige, F., N. Tanaka, A. Maki, S. Kaei and M. Yamanaka (1981). Direct spectrophotometry of total bile acids in serum. Clin. Chem. 27, 1352-1356.

Merimee, T. J. and D. Rabin (1973). A survey of growth hormone secretion and action. $\mathrm{Me}$ - tabolism. 22, 1235-1251.

Merimee, T. J. and A. Pulkkinen (1980). Familial combined hyperlipoproteinemia, evidence for a role of growth hormone deficency in effecting its manifestation. J. Clin. Invest. 65, 829-835.

Meyers, W. C., J. B. Hanks and R. S. Jones (1979). Inhibition of basal and meal-stimulated choleresis by somatostain. Surgery 86, 301306.

Raiti, S. and R. M. Blizzard (1970). Human growth hormone: Current knowledge regarding its role in normal and abnormal metablic state. Adv. Pediatr. 17, 99-123.

Rene, E., R. G. Dazinger, A. F. Hofmann and M. Nakagaki (1983). Pharmacologic effect of somatostatin on bile formation in dog. Gastroenterology 84, 120-129.

Ricci, G. L. and J. J. Fevery (1981). Cholestatic action of somatostatin in the rat: effect on the different fractions of bile secretion. Gastroenterology 81, 552-562.

Richmond, W. (1973). Preparation and properties of a cholesterol oxidase from Nocardia sp. and its application to the enzymatic assay of total cholesterol in serum. Clin. Chem. 19, 1350-1356.

Riely, C. A., E. Cortlier, P. S. Gensen and G. Klatskin (1979). Arteriohepatic dysplasia : a benign syndrome of intrahepatic cholestasis with multiple organ involvement. Ann. Intern. Med. 91, 520-527.

Porter, B. A., S. Refetoff, R. L. Rosenfield, L. J. De Groat, U. S. Alang and O. Stark (1973). Abnormal thyroxine metabolism in hyposomatotrophic dwarfism and inhibition of responsiveness to TRH during GH therapy. Pediatrics 51, 668-674.

Takayama, M., S. Itoh, T. Nagasaki and I. Tanimizu (1977). A new enzymatic method for determination of serum cholin-containing phospholipids. Clinica. Cheminica. Acta 79, 93-98.

Watson, G. H. and V. Miller (1973). Arteriohepatic dysplasia. Familial pulmonary arterial stenosis with neonatal liver disease. Arch. Dis. Child. 48, 459-466.

Winter, R. J., R. G. Thompson and O. C. Green (1979). Serum cholesterol and triglyceride in children with growth hormone deficiency. Metabolism 28, 1244-1249. 